\title{
NOBEL LAUREATES
}

\section{Prof. R. Kuhn}

Prof. Richard Kuns, who has been awarded the Nobel prize for chemistry for 1938, is Viennese by birth and $a$ pupil of Willstätter. He has been head of the Department of Chemistry of the Kaiser. Wilhelm Institut für Medizinische Forschung in Heidelberg since the Institute was opened in 1930 , and, after the death of von Krehl, was made director of the Institute in 1937. Kuln's work does not consist of ono single great achiovement, although ho has mado important contributions to many problems in organic and biochemistry. His early work was concerned with enzymes and with stereochemical problems. He has done important work on the polyenes, of the general formula $\mathrm{C}_{6} \mathrm{H}_{6}(\mathrm{CH}=\mathrm{CH})_{n}$ $\mathrm{C}_{6} \mathrm{H}_{5}$, which ho was able to synthesize up to $n=15$. It was thus possible to gain information on tho behaviour of long chains of conjugated double bonds, which are also of interest in other fields of work such as photographic sensitizers.

Kuhn has also worked out tho synthesis of a new class of chemical compounds, the cumu. lenes. This work led up to a synthesis of vitamin $A$, which was preceded by investigations on the constitution of carotene. He recognized at about the same time as $O$. Warburg that the prosthetic group of a yellow ferment which is responsible for the degradation of sugar phosphoric acid esters is present in vitamin $B_{2}$. With the synthesis of lactiflavine-5'-phosphoric acid, he achieved the preparation of the active group of an enzyme. Through the application of boric acid in the condensation with alloxan, he was able to increase the yield up to about 90 per cent of the theoretical value. His most recent work is concerned with the chemical nature of sex substances necessary for the copulation of gametes of various alga. Specific carotinoids, such as crocin and cis- and trans-crocetin-dimethylester, are essential for the mobility of the Protozoa under anarobic conditions and for the process of copulation. Prof. Kuhn is well known in Great Britain, and he delivered the sixth Pedler Lecture of the Chemi. cal Society in 1938, when he discussed the synthesis of polyenes.

\section{Prof. A. Butenandt}

Prof. Adorf Butenandr, who shares this year's Nobel prize for chemistry with Prof. L. Ruzicka, is well known in Great Britain. For a number of years Prof. Butenandt held the position of Privat Dozent in the Department of Chemistry of the University of Göttingen under Prof. A. Vindaus. There can bo littlo doubt that his association with this laboratory, the work of which had been devoted to the elucidation of the structure of the sterols for so many years, played an important part in his success in determining the constitution of oestrone. It was while he was at Göttingen that Aschheim and Zondek made their classical discovery of the presence in the urine of pregnancy of large quantities of cstrogenic material. It was found to be in a purer stato and more subject. to processes of purification than when extracted from the ovaries or follicular fluid. The large-scale com. mercial collection of this material in Germany rendered available in 1928 quantities of starting material. To Butenandt fell the task of elucidating tho structure, and in 1929 he succeeded in obtaining the compound in a crystalline form.

THe announcement was made simultaneously with that of the independent discovery of a crystalline material by Doisy in the United States. Marrian in Great Britain had also obtained a crystalline sub. stance, but it was found later to be of a different constitution from the crystals of Butenandt and Doisy. The work of Butenandt on the selenium treatment of cestrone resulted in the demonstration of the presence of the phenanthrene ring system, and a classical paper on this was communicated to a meeting of the Chemical Society held in London in March 1933. Later Butenandt worked on the con. stitution of the male sex hormone. He isolated androsterone in the crystalline form and proved its constitution, and his work on progesterone and other derivatives of the sterols forms the background of this important development in chemistry. He left Göttingen to take the chair at Danzig, and was for a fow years professor of chemistry in that University. Some two years ago he was appointed director of the Kaiser.TVilhelm Institut of Biochemistry in Berlin, which position he now holds. Many of our readers will remember the three lectures Prof. Butenandt delivered at the I.ondon School of Hygiene and Tropical Medicine in 1936, lectures which were noted for their clarity of style and for their excellent delivery in faultless Finglish.

\section{Prof. L. Ruzicka}

Prof. L. Ruzicka, professor of chemistry in the Federal Technical Highschool of Zurich, has a long record of brilliant investigations in the field of pure organic chemistry. Without doubt, lowever, the present award is mainly on account of his development of the degradation synthesis of hormones from sterols. It will be remembered that the workers at Göttingen devoted many years to the elucidation of the structure of the side-chain of the sterols, it being well known that these could be removed by appropriate chemical treatment. The recognition of the structure of progesterone, testosterone, corticosterono and other highly active hormones of the steroid group led organic chemists to attempt their synthesis. The formidable nature of this task will readily be appreciated, since not only is the cyclopentenophenan. threne system, with double bonds, polar groups and so on, an extremely difficult object for synthetic 
attack, but ulso there is an almost infinite number of stereo-chemical isomers due to the presence of cyclohexane rings. It occurred to Ruzicka that the ring system of the sterols might provide the basis for the synthesis of hormones, and he thereforo chose a sterol with a suitable stereo-chemical configuration for the ring system and removed the side chain by oxidation. This provided a most important basis for the synthesis of the hormones, and by suitable manipulation of double bonds, conversion of hydroxyl groups to keto groups, and so on, it was possible to produce from a neutral sterol such as cholesterol the highly potent hormone testosterone. It can be said that the recognition of this principle has solved the problem of hormone production, quite apart from its great theoretical interest. Prof. Ruzicka has been a frequent visitor to Great Britain; his addresses are noted for their clarity and for their wit.

\section{Prof. E. O. Lawrence}

Tre announcement of the award of the Nobel Prize for physics for 1939 to Prof. E. O. Lawrence, professor of physics in the University of California, Berkeley, will be received by physicists everywhere with approbation. Lawrence's early researches wero concerned with photo-electric effects but, in 1930, he became interested in the possibilities of using the method of resonance acceleration in order to obtain positive ions of very high energies, by means of a number of consecutive accelerations through relatively low differences of potential. The method of linear resonance acceleration was pushed to its practical limit in Lawrence's laboratory when, in 1934, mercury ions wero obtained having energies equivalent to accelerations through a potential difference of nearly three million volts, using, however, applied potential differences having a peak value of only 79,000 volts. The limitations of the method of linear resonance acceleration in its application to the acceleration of ions of small atomic mass had, however, been recognized by Lawrence in 1930, in which year he proposed a modi. fication of the method for such ions. This consisted in accelerating the ions back and forth between two semi-cylindrical hollow conductors, the paths of the ions being rendered circular by means of an intense magnetic field. Thus was conceived the magnetic resonance accelerator, or cyclotron as it is now more generally called.

AT that time, it was somewhat generally considered that the practical difficulties involved in the cyclotron were of a magnitude likely to preclude the translation of this conception into terms of practical physics. All the greater then, was the tribute to be paid to the experimental genius of Lawrence when, little more than a year later, he announced the success of the method in obtaining light ions of high energy. His success was acclaimed on both sides of the Atlantic, by the awards of the Comstock Prize of the National Academy of Sciences in 1937 and, in the following year, of the Hughes Medal of the Royal Society, the latter being given for "the most impor. tant instrument of physical research since the C. T. R. Wilson expansion chamber". Later, howover, Lawrence's interest turned rather towards the vast field of physiological research to which the cyclotron, with its prolific output of radioactive indicators, had opened up a new approach. Important results in nuclear physics continued to pour from the Radiation Laboratory at Berkeley, but at the same timo a new side was being doveloped, and the physiological effects of neutrons and the metabolism of phosphorus and iron, and of like elements which could be obtained in a radioactive form, were being exhaustively studied. Not to Lawrence's laboratory alone was this work confined, his generosity providing for scientific workers in many places in America and in Europe as much radioactivo material as they could conveniently use. Lawrence is not only a respected director of a research laboratory but, above all, a valued friend of those who have worked with him.

The 1939 Nobel Prize for literature has been awarded to N. Frans E. Sillanpää, the Finnish novelist. His novels aro based chiefly on the peasant life of Finland. The Nobel Prize for Physiology and Medicine for 1938 was awarded to Prof. C. Heymans, and that for 1939 to Prof. G. Domagk (Nature, November 4, p. 777).

\section{NEWS AND VIEWS}

\section{Royal Medals of the Royal Society}

His MaJesty THE KrxG has been graciously pleased to approve the recommendations made by the Council of the Royal Society for the award of the two Royal Medals for the current year as follows : Prof. P. A. MI. Dirac, F.R.S., Lucasian professor of mathematics in the University of Cambridge, for the leading part he has taken in the development of the new quantum mechanics; Prof. D. Keilin, F.R.S., Quick professor of biology and director of the Molteno Institute in the University of Cambridge, for his con. tributions to biochemistry and entomology, in particular for his demonstration of the part played by cytochrome in the oxidation reduction mechanisms of the living cell, and for his studies of the higher Diptera.

\section{Centenary Celebrations in New Zealand}

Is December 1642, Europeans first discorered New Zealand, although they mistook its general character. A century and a half later their mistake was rectified by Captain Cook. His reports attracted 